\title{
PENGARUH MEDIA PEMBELAJARAN PADA MATA PELAJARAN ILMU PENGETAHUAN SOSIAL TERHADAP HASIL BELAJAR MURID KELAS IV
}

\author{
Rismawati, Rubianto \\ Pendidikan Guru Sekolah Dasar, Fakultas Keguruan dan Ilmu Pendidikan \\ Universitas Muhammadiyah Makassar \\ rubiantosaputra@gmail.com
}

\begin{abstract}
ABSTRAK
Jenis penelitian ini adalah penelitian eksperimen bentuk Pre test Post test Design yaitu sebuah eksperimen yang dalam pelaksanaannya hanya melibatkan satu kelas sebagai kelas eksperimen tanpa adanya kelas pembanding (kelas kontrol) yang bertujuan untuk mengetahui pengaruh penggunaan media pembelajaran pada Mata Pelajaran IPS terhadap hasil belajar Murid kelas 1V SD Inpres Tamarunang Kecamatan Eremerasa Kabupaten Bantaeng tahun ajaran 2016/2017. Satuan eksperimen dalam penelitian ini adalah murid Kelas 1V sebanyak 15 orang. Penelitian dilaksanakan selama 5 kali pertemuan. Keberhasilan proses pembelajaran ditinjau dari aspek, yaitu: ketercapaian ketuntasan hasil belajar IPS murid secara klasikal, aktivitas siswa dalam pembelajaran IPS. Pembelajaran dikatakan berhasil jika aspek di atas terpenuhi. Teknik pengumpulan data yang digunakan adalah data hasil belajar IPS murid yang dikumpulkan dengan menggunakan tes hasil belajar, data tentang aktivitas murid dalam pembelajaran IPS dikumpulkan dengan menggunakan lembar observasi aktivitas belajar murid. Hasil analisis statistik deskriptif terhadap hasil belajar murid terhadap media pembelajaran gambar positif, pemahaman materi dan konsep dari IPS dengan media gambar ini menunjukkkan hasil belajar yang lebih baik dari pada sebelum menggunakan media gambar. Hasil analisis statistik inferensial menggunakan rumus uji $t$, diketahui bahwa nilai $t$ Hitung yang diperoleh adalah 15,75 dengan frekuensi $d b=15-1=14$, pada taraf signifikansi $5 \%$ diperoleh $t_{\text {tabel }}=1,78$. Jadi, $t_{\text {Hitung }}>$ $t_{\text {tabel }}$ atau hipotesis nol $\left(\mathrm{H}_{0}\right)$ ditolak dan hipotesis alternative $\left(\mathrm{H}_{1}\right)$ diterima yang bebunyi bahwa penggunaan media pembelajaran mempengaruhi hasil belajar IPS. Hal ini membuktikan bahwa penggunaan media gambar dalam pembelajaran IPS mempunyai pengaruh dari pada sebelum menggunakan media gambar.
\end{abstract}

Kata kunci: Eksperimen, Media Gambar,Pembelajaran IPS. 


\section{PENDAHULUAN}

Pendidikan adalah suatu bidang yang harus diutamakan oleh setiap negara, sebab menyangkut kehidupan masa depan bangsa. Pendidikan di Indonesia menjadi kompleks karena di dalamnya berbagai hal yang sangat terkait satu sama lain. Pendidikan itu sendiri berkembang seiring dengan perkembangan dan kemajuan ilmu pengetahuan dan teknologi (IPTEK) saat ini. Untuk itu mutlak diperlukan adanya sebuah sistem pendidikan yang diatur undang-undang agar tercipta keseragaman nasional serta keberhasilan program pendidikan itu sendiri.

Media pembelajaran merupakan salah satu komponen pembelajaran yang mempunyai peranan penting dalam kegiatan belajar mengajar. Pemanfaatan media seharusnya merupakan bagian yang harus mendapat perhatian bagi stiap guru khususnya dalam kegiatan pembelajaran. Oleh karena itu guru perlu mempelajari bagaimana menetapkan media pembelajaran agar dapat mengefektifkan pencapaian tujuan pembelajaran dalam proses belajar mengajar. Dengan demikian media pembelajaran ini dapat membantu guru dalam menyampaikan materi pelajaran dan menyajikan pelajaran yang dapat mendukung aktivitas belajar siswa terhadap materi secara optimal dan memberikan gairah dalam belajar agar dapat merangsang proses belajar mengajar yang berlangsung secara efektif dan efisien, sebab dalam proses belajar mengajar kriteria yang berhasil di tandai dengan terjadinya perubahan tingkah laku pada diri individu yang belajar. Seorang guru dikatakan berhasil, bila seorang guru dapat memilih media pembelajaran yang cocok untuk digunakan pada mata pelajaran khususnya IPS.

Dalam mata pelajaran IPS, pada dasarnya memang materinya sebagian besar bisa dilakukan hanya dengan metode ceramah dan metode textbook. Tapi untuk memberikan kesan nyata agar para peserta didik dapat dengan mudah mengingat dan memahami suatu materi pembelajaran yang dibahas oleh guru yang memberikan materi pembelajaran. Kesan nyata memang diperlukan untuk lebih membantu anak bersikap kritis dan berfikir logis dalam mata pelajaran IPS, dan untuk menunjang kesan nyata dalam pelajaran IPS sebaiknya guru menggunakan sebuah media pembelajaran bantu berupa media pembelajaran yang sesuai 
dengan pokok bahasan yang akan diajarkan.

Dengan penggunaan media pembelajaran anak didik (murid) akan dapat termotivasi dalam kegiatan belajar mengajar, juga akan dapat lebih cepat dalam memahami dan mengerti tentang materi yang diajarkan dengan media pembelajaran tersebut. Anak didik (murid) kita pun diyakini akan lebih bergairah dan senang dengan tampilan dan pengalaman dari yang dilihatnya dan didengarnya melalui media pembelajaran tersebut. Dengan alat bantu media pembelajaran diharapkan akan mampu dalam merangsang daya pikir yang bersifat kreatif dan kritis bagi anak didik (murid) sehingga akan memberikan suatu umpan balik antara tenaga pendidik (guru) dan anak didik (murid). Sehingga berbagai macam masalah dan kesenjangan yang terjadi dapat diminimalisasi dan murid-murid pun akan lebih mudah mendapatkan hasil belajar yang mereka harapkan.

Berdasarkan uraian di atas rumusan masalah dalam penelitian ini adalah "Apakah penggunaan media pembelajaran berpengaruh terhadap hasil belajar IPS pada murid kelas IV ?. Tujuan penelitian ini adalah untuk mengetahui pengaruh Media
Pembelajaran Pada Mata Pelajaran IPS terhadap hasil belajar murid kelas IV SD.

\section{Media Pembelajaran}

Kata media berasal dari bahasa latin medius yang secara harfiah berarti 'tengah', 'perantara', atau 'pengantar'. Secara lebih khusus, pengertian media dalam proses belajar mengajar cenderung diartikan sebagai alat-alat grafis, photografis, atau elektronik untuk menangkap, memproses, dan menyusun kembali informasi visual atau verbal.

Pengertian media pembelajaran adalah paduan antara bahan dan alat atau perpaduan antara software dan hardware (Sadiman, dkk, 1996: 5). Media pembelajaran bisa dipahami sebagai media yang digunakan dalam proses dan tujuan pembelajaran. Pada hakikatnya proses pembelajaran juga merupakan komunikasi, maka media pembelajaran bisa dipahami sebagai media komunikasi yang digunakan dalam proses komunikasi tersebut, media pembelajaran memiliki peranan penting sebagai sarana untuk menyalurkan pesan pembelajaran.

Jadi media pembelajaran adalah segala sesuatu yang digunakan untuk menyaluarkan pesan serta dapat memotivasi dan merangsang pikiran, 
perasaan, perhatian murid sehingga dapat mendorong terjadinya proses belajar mengajar yang di sengaja, bertujuan dan terkendali.

\section{Hasil Belajar}

Jika dikaitkan dengan belajar IPS maka hasil belajar terjadi karena evaluasi yang dilakukan guru dalam mempelajari IPS. Agar dapat menentukan tercapai tidaknya tujuan pendidikan dan pengajaran maka perlu dilakukan usaha dan tindakan atau kegiatan untuk menilai hasil belajar.

Menurut Yusanto dkk, menyangkut penilaian hasil belajar akan memperlihatkan tingkat penguasaan dan pemahaman konsep, perwujudan sikap dan partisipasi dalam interaksi sosial secara nyata. Sedangkan menurut Bloom mengemukakan bahwa hasil belajar mencakup kemampuan kognitif, afektif, dan psikomotorik (Said, 2013 : 12).

Jadi hasil belajar IPS adalah tingkat keberhasilan siswa menguasai bahan pelajaran IPS setelah memperoleh pengalaman belajar IPS yang dapat diukur secara langsung dengan menggunakan tes.

\section{METODE PENELITIAN}

Penelitian ini merupakan penelitian eksperimen. Desain pada penelitian ini adalah satu kelompok pretest-post test (The one group pretest-post test design) yang termasuk dalam penelitian pra eksperimen.

Populasi dalam penelitian ini adalah seluruh siswa kelas IV SD Inpres Tamarunang Kecamatan Eremeras Kabupaten Bantaeng dengan jumlah populasi sebanyak 15 siswa. Sampel dalam penelitian ini adalah siswa kelas IV SD Inpres Tamarunang Kecamatan Eremeras Kabupaten Bantaeng, yang berjumlah 15 siswa, siswa laki-laki 6 orang dan siswa perempuan 9 orang.. Instrumen dalam penelitian ini adalah tes berbentuk soal pertanyaan yang digunakan untuk pengukur pencapaian siswa setelah proses pembelajaran yang dilakukan akhir tindakan pada kelas eksperimen. Untuk menganalisis data yang diperoleh dari hasil penelitian akan digunakan analisis statistik deskriptif dan inferensial.

\section{HASIL PENELITIAN DAN} PEMBAHASAN

Deskripsi Hasil Pretest IPS Murid Kelas IV Sebelum Menggunakan Media Gambar

Berdasarkan hasil penelitian yang dilakukan oleh peneliti di kelas IV SD Inpres Tamarunang Kecamatan Eremerasa Kabupaten Bantaeng, maka 
diperoleh data-data yang dikumpulkan melalui instrumen tes sehingga dapat diketahui hasil belajar murid berupa nilai dari murid kelas IV SD Inpres Tamarunang Kecamatan Eremerasa Kabupaten Bantaeng.

Tabel 1 Deskripsi Skor Tes Kemampuan Awal murid kelas IV SD Inpres Tamarunang Kecamatan Eremerasa Kabupaten Bantaeng.

\begin{tabular}{|c|c|}
\hline Statistik & NilaiStatistik \\
\hline Sampel & 15 \\
Skor Ideal & 100 \\
Skor Maksimum & 90 \\
Skor Minimum & 33 \\
Rentang Skor & 57 \\
Skor Rata-rata & 62,4 \\
\hline
\end{tabular}

Berdasarkan Tabel 1 di atas diperoleh informasi bahwa skor ratarata tes kemampuan awal siswa sebelum diajar dengan menggunakan media gambar adalah 62,4 dari skor ideal 100. Skor tertinggi yang dicapai siswa adalah 90 dan skor terendah adalah 33.

Adapun dikategorikan pada pedoman Departemen pendidikan dan kebudayaan (Depdikbud), maka keterangan murid dapat dilihat pada tabel berikut:
Tabel 2. Tingkat Penguasaan Materi Pretest

\begin{tabular}{|r|c|c|c|c|}
\hline No & Interval & Frekuensi & $\begin{array}{c}\text { Persentase } \\
(\%)\end{array}$ & $\begin{array}{c}\text { kategori } \\
\text { hasil } \\
\text { belajar }\end{array}$ \\
\hline 1. & $0-34$ & 1 & 6,67 & $\begin{array}{c}\text { Sangat } \\
\text { rendah }\end{array}$ \\
\hline 2. & $35-54$ & 5 & 33,33 & Rendah \\
\hline 3. & $55-64$ & 2 & 13,33 & Sedang \\
\hline 4. & $65-84$ & 4 & 26,67 & Tinggi \\
\hline 5. & $85-100$ & 3 & 20 & Sangat \\
& & 15 & 100 & tinggi \\
\hline Jumlah & & & & \\
\hline
\end{tabular}

Berdasarkan data yang dapat dilihat pada tabel di atas maka dapat disimpulkan bahwa hasil belajar murid pada tahap pretest dengan menggunakan instrumen test dikategorikan sangat rendah yaitu $6,67 \%$, rendah $33,33 \%$, sedang $13,33 \%$, tinggi $26,67 \%$ dan sangat tingggi berada pada presentase $20 \%$. Melihat dari hasil presentase yang ada dapat dikatakan bahwa tingkat kemampuan murid dalam memahami serta penguasaan materi pelajaran IPS sebelum menggunakan media gambar tergolong rendah.

Tabel 3 Deskripsi Ketuntasan Hasil Belajar IPS

\begin{tabular}{|l|l|l|l|}
\hline Skor & Kategorisasi & Frekuensi & $\%$ \\
& & & \\
\hline
\end{tabular}




\begin{tabular}{|c|c|c|c|}
\hline $\begin{array}{l}0 \leq x< \\
64\end{array}$ & Tidak tuntas & 8 & 53,33 \\
\hline $\begin{array}{l}65 \leq x \\
\leq 100\end{array}$ & Tuntas & 7 & 46,67 \\
\hline Jun & & 15 & 100 \\
\hline
\end{tabular}

Apabila Tabel 3 dikaitkan dengan indikator kriteria ketuntasan hasil belajar murid yang ditentukan oleh peneliti yaitu jika jumlah murid yang mencapai atau melebihi nilai KKM (65) $\geq 65 \%$, sehingga dapat disimpulkan bahwa hasil belajar IPS kelas IV SD Inpres Tamarunang Kecamatan Eremerasa Kabupaten Bantaeng belum memenuhi kriteria ketuntasan hasil belajar secara klasikal dimana murid yang tuntas hanya $46,67 \% \leq 65 \%$.

\section{Deskripsi Hasil Belajar (posttest) IPS}

Kelas IV Setelah Menggunakan Media

\section{Gambar}

Selama penelitian berlangsung terjadi perubahan terhadap kelas setelah diberikan perlakuan.Perubahan tersebut berupa hasil belajar yang datanya diperoleh setelah diberikan post-test.

Tabel 4 Deskripsi Posttest Skor Hasil Belajar murid kelas IV SD Inpres Tamarunang Kecamatan Eremerasa Kabupaten Bantaeng.

\begin{tabular}{|c|c|}
\hline Statistik & Nilai Statistik \\
\hline Sampel & 15 \\
\hline
\end{tabular}

\begin{tabular}{|c|c|}
\hline Skor Ideal & 100 \\
\hline Skor Maksimum & 100 \\
\hline Skor Minimum & 50 \\
\hline Rentang Skor & 50 \\
\hline Skor Rata-rata & 80,67 \\
\hline
\end{tabular}

Berdasarkan Tabel4 di atas diperoleh informasi bahwa skor ratarata tes kemampuan awal siswa setelah diajar dengan menggunakan media gambar adalah 80,67 dari skor ideal 100. Skor tertinggi yang dicapai siswa adalah 100 dan skor terendah adalah 50.

Adapun di kategorikan pada pedoman Departemen pendidikan dan kebudayaan (Depdikbud), maka keterangan murid dapat dilihat pada tabel berikut:

Tabel 5 Tingkat Penguasaan Materi

Post-test

\begin{tabular}{|c|c|c|c|c|}
\hline No & interval & Frekuensi & $\begin{array}{c}\text { Persentase } \\
(\%)\end{array}$ & $\begin{array}{c}\text { Kategori } \\
\text { hasil } \\
\text { belajar }\end{array}$ \\
\hline 1. & $0-34$ & - & 0,00 & $\begin{array}{c}\text { Sangat } \\
\text { rendah }\end{array}$ \\
\hline 2. & $35-54$ & 1 & 6,67 & Rendah \\
\hline 3. & $55-64$ & 4 & 26,67 & Sedang \\
\hline 4. & $65-84$ & 3 & 20 & Tinggi \\
\hline 5. & $85-100$ & 7 & 46,67 & $\begin{array}{c}\text { Sangat } \\
\text { tinggi }\end{array}$ \\
\hline \multicolumn{2}{|c|}{ Jumlah } & 15 & 100,0 & \\
\hline
\end{tabular}

Berdasarkan data yang dapat dilihat pada tabel di atas maka dapat 
disimpulkan bahwa hasil belajar pada tahap post-test dengan menggunakan instrumen test dikategorikan sangat tinggi yaitu 46,67\%, tinggi 20\%, sedang $26,67 \%$, rendah $6,67 \%$, dan sangat rendah berada pada presentase $0,00 \%$. Melihat dari hasil presentase yang ada dapat dikatakan bahwa tingkat kemampuan murid dalam memahami serta penguasaan materi pelajaran IPS setelah menggunakan media gambar tergolong sangat tinggi.

Tabel 6 Deskripsi Ketuntasan Hasil Belajar IPS

\begin{tabular}{|l|c|c|c|}
\hline Skor & Kategorisasi & Frekuensi & $\%$ \\
\hline $\begin{array}{l}0 \leq \times \\
<64\end{array}$ & Tidak tuntas & 5 & 33,33 \\
\hline $\begin{array}{l}65 \leq \\
\times \leq \\
100\end{array}$ & Tuntas & 10 & 66,67 \\
\hline \multicolumn{2}{|c|}{ Jumlah } & 15 & 100 \\
\hline
\end{tabular}

Apabila Tabel 6 dikaitkan dengan indikator kriteria ketuntasan hasil belajar murid yang ditentukan oleh peneliti yaitu jika jumlah murid yang mencapai atau melebihi nilai KKM (65) $\geq 65 \%$, sehingga dapat disimpulkan bahwa hasil belajar IPS Kelas IV SD Inpres Tamarunang Kecamatan
Eremerasa Kabupaten Bantaeng telah memenuhi kriteria ketuntasan hasil belajar secara klasikal dimana murid yang tuntas adalah $66,67 \% \geq 65 \%$.

\section{Pengaruh Penggunaan Media Gambar Terhadap Hasil Belajar IPS Murid} Kelas IV

Sesuai dengan hipotesis penelitian yakni "penggunaan media gambar memiliki pengaruh terhadap hasil belajar IPS murid kelas IV SD Inpres Tamarunang Kecamatan Eremerasa Kabupaten Bantaeng".Maka teknik yang digunakan untuk menguji hipotesis tersebut adalah teknik statistik inferensial dengan menggunakan uji-t.

Langkah-langkah dalam pengujian hipotesis adalah sebagai berikut:

1. Mencari harga "Md" dengan menggunakan rumus:

$$
\begin{aligned}
\operatorname{Md} & =\frac{\sum d}{N} \\
& =\frac{274}{15} \\
& =18,27
\end{aligned}
$$

2. Mencari harga " $\sum X^{2} d$ " dengan menggunakan rumus:

$$
\sum X^{2} d=\sum d^{2}-\frac{\left(\sum d\right)^{2}}{N}
$$




$$
\begin{aligned}
& =528-\frac{(274)^{2}}{15} \\
& =5286-\frac{75076}{15} \\
& =5286-5005,07 \\
& =280,93
\end{aligned}
$$

3. Menentukan harga $t_{\text {Hitung }}$

$$
\begin{aligned}
& \mathrm{t}=\frac{M d}{\sqrt{\frac{\sum X^{2} d}{N(N-1)}}} \\
& \mathrm{t}=\frac{18,27}{\sqrt{\frac{280,93}{15(15-1)}}} \\
& \mathrm{t}=\frac{18,27}{\sqrt{\frac{280,93}{210}}} \\
& \mathrm{t}=\frac{18,27}{\sqrt{1,34}} \\
& \mathrm{t}=\frac{18,27}{1,16} \\
& \mathrm{t}=15,75
\end{aligned}
$$

4. Menentukan harga $t_{\text {Tabel }}$

Untuk mencari $t$ Tabel peneliti menggunakan tabel distribusi t dengan taraf signifikan $\alpha=0,05$ dan $d . b=N-$ $1=15-1=14$ maka diperoleh $t_{0,05}=$ 1,78 .

Setelah diperoleh $t_{\text {Hitung }}=15,75$ dan $\mathrm{t}_{\text {Tabel }}=1,78$ maka diperoleh $\mathrm{t}_{\text {Hitung }}>$ $\mathrm{t}_{\text {Tabel }}$ atau 15,75 > 1,78. Sehingga dapat disimpulkan bahwa $\mathrm{H}_{0}$ ditolak dan $\mathrm{H}_{1}$ diterima. Ini berarti bahwa penggunaan media gambar berpengaruh terhadap hasil belajar murid.

Berdasarkan hasil pre-test, nilai rata-rata hasil belajar murid 62,4 dengan kategori sangat rendah yaitu 6,67\%, rendah 33,33\%, sedang 13,33\%, tinggi 26,67\% dan sangat tingggi berada pada presentase 20\%. Melihat dari hasil presentase yang ada dapat dikatakan bahwa tingkat kemampuan murid dalam memahami serta penguasaan materi pelajaran IPS sebelum menggunakan media gambar tergolong rendah.

Selanjutnya nilai rata-rata hasil post-test adalah 80,67. Jadi hasil belajar IPS setelah menggunakan media gambar mempunyai hasil belajar yang lebih baik dibanding dengan sebelum menggunakan media gambar. Selain itu persentasi kategori hasil belajar IPS murid juga meningkat yakni sangat tinggi yaitu 46,67\%, tinggi $20 \%$, sedang $26,67 \%$, rendah $6,67 \%$, dan sangat rendah berada pada presentase $0,00 \%$.

Berdasarkan hasil analisis statistik inferensial dengan menggunakan rumus uji $t$, dapat diketahui bahwa nilai $t_{\text {hitung }}$ sebesar 15,75. Dengan frekuensi ( $\mathrm{dk}$ ) sebesar 15 - $1=14$, pada taraf signifikansi 5\% diperoleh $t_{\text {tabel }}=1,78$. Oleh karena $t_{\text {hitung }}$ $>t_{\text {tabel }}$ pada taraf signifikansi 0,05, maka hipotesis nol $\left(\mathrm{H}_{0}\right)$ ditolak dan hipotesis alternative $\left(\mathrm{H}_{1}\right)$ diterima yang berarti bahwa penggunaan media gambar mempengaruhi hasil belajar IPS. 
Hasil observasi menunjukkan banyaknya jumlah murid yang menjawab pada saat diajukan pertanyaan dan murid yang mengajukan diri untuk mengerjakan soal di papan tulis. Murid juga mulai aktif dan percaya diri untuk menanggapi jawaban dari murid lain sehingga murid yang lain ikut termotivasi untuk mengikuti pelajaran. Proses pembelajaran yang menyenangkan membuat murid tidak lagi keluar masuk pada saat pembelajaran berlangsung.

Berdasarkan hasil analisis statistik deskriptif dan statistik inferensial yang diperoleh serta hasil observasi yang telah dilakukan, dapat disimpulkan bahwa penggunaan media gambar memiliki pengaruh terhadap hasil belajar IPS siswa kelas kelas IV SD Inpres Tamarunang Kecamatan Eremerasa Kabupaten Bantaeng.

\section{KESIMPULAN}

Simpulan yang lebih rinci berkaitan pelaksanaan pembelajaran ilmu pengetahua sosial dengan menggunakan media gambar kelas kelas IV SD Inpres Tamarunang Kecamatan Eremerasa Kabupaten Bantaeng berdasarkan data yang diperoleh dapat disimpulkan bahwa secara umum hasil belajar murid kelas kelas IV SD Inpres Tamarunang
Kecamatan Eremerasa Kabupaten Bantaeng sebelum menggunakan media gambar dikategorikan rendah. Hal ini ditunjukkan dari perolehan persentase hasil belajar siswa yaitu sangat rendah yaitu $6,67 \%$, rendah $33,33 \%$, sedang $13,33 \%$, tinggi $26,67 \%$ dan sangat tingggi berada pada presentase $20 \%$. Sedangakan berdasarkan data yang diperoleh setelah menggunakan media gambar bahwa secara umum berpengaruh terhadap hasil belajar IPS kelas kelas IV SD Inpres Tamarunang Kecamatan Eremerasa Kabupaten Bantaeng dapat dilihat dari perolehan persentase yaitu sangat tinggi yaitu $46,67 \%$, tinggi $20 \%$, sedang $26,67 \%$, rendah 6,67\%, dan sangat rendah berada pada presentase $0,00 \%$. Jadi berdasarkan uji hipotesis yang telah dilakukan dapat disimpulkan bahwa penggunaan media gambar memiliki pengaruh terhadap hasil belajar IPS kelas kelas IV SD Inpres Tamarunang Kecamatan Eremerasa Kabupaten Bantaeng dengan perolehan $t_{\text {Hitung }}=$ 15,75 dan $t_{\text {Tabel }}=1,78$ maka diperoleh $t_{\text {Hitung }}>\mathrm{t}_{\text {Tabel }}$ atau 15,75 $>1,78$.

Berdasarkan temuan yang berkaitan hasil penelitian penggunaan media gambar yang mempengaruhi hasil belajar IPS kelas kelas IV SD Inpres Tamarunang Kecamatan Eremerasa 
Kabupaten Bantaeng, maka dikemukakan beberapa saran sebagai berikut :Kepada para pendidik khususnya guru kelas IV SD Inpres Tamarunang Kecamatan Eremerasa Kabupaten Bantaeng, disarankan untuk menggunakan media gambar dalam pembelajarannya agar dapat membangkitkan minat dan motivasi siswa untuk belajar. Kepada Peneliti, diharapkan mampu mengembangkan media gambar ini pada mata pelajaran lain demi tercapainya tujuan yang diharapkan. Kepada calon Peneliti, akan dapat mengembangkan media pembelajaran ini serta memperkuat hasil penelitian ini dengan cara mengkaji terlebih dahulu dan mampu mengadakan penelitian yang lebih sukses.

\section{DAFTAR PUSTAKA}

Arikunto. 2010. Prosedur Penelitian (Satuan Pendekatan Praktik). Jakarta: Rineka Cipta.

Aunurrahman. 2012. Belajar Dan Pembelajaran. Bandung: Alfabeta.

Deway, John. 1916. Democracy an Education. Jakarta : Alfabeta.

Dimyati, Mudjiono. 1999. Belajar dan Pembelajaran. Jakarta : Rineka Cipta.

Djumingin, Sulastriningsih .2011. Model Pembelajaran Inovatif Bahasa dan Sastra.Makassar: Universitas Negeri Makassar.

Ibrahim.M.,dkk. 2000. Pembelajaran Kooperatif. Surabaya : UNESA.

Iskandarwassid dan H. Sunender, D. 2008. Srategi Pembelajaran Bahasa. Bandung: PT Remaja Rosdakarya.

Mulyatiningsih, Endang. 2013. Metode Penelitian Terapan Bidang Pendidikan. Bandung: Alfabeta.

Nurhadi. Dkk. 2003. Pembelajaran Konstektual (Contextual Teaching and Learning dan penerapan dalam KBK. Malang: Universitas Negeri Malang

Slavin,R.E.2008.Cooperative Leraning. Bandung: Nusamedia.

Santosa, Puji. Materi dan Pembelajaran Bahasa Indonesia SD. Jakarta: Universitas Terbuka. 2004.

Sugiyono. 2014. Metode Penelitian Pendidikan. Bandung: Alfabeta.

Syamsuri, Andi Sukri. dkk. 2012. Pedoman Penulisan Skripsi. Makassar. Panitia Press Unismuh Makassar.

Trianto.2009. Desain Model PembelajaranI novatif-Progresif. Jakarta: Kencana

Yania,Risdiawati.2012.Implementasi ModelPembelajaran Kooperatif Tipe Student Teams Achievement Divisions (STAD) untuk Meningkatkan Motivasi dan Hasil Belajar Akuntansi Siswa Kelas XI IPS 4 SMA Negeri 1 Imogiri Tahun Ajaran 2011/2012. Skripsi. Universitas Negeri Yogyakarta. 